Gynäk. Rdsch. 1982;22(Suppl. 1):172-173

\title{
Alphafetoprotein-Screening in der Frühschwangerschaft
}

\begin{tabular}{|l|l|l|}
\hline J.C. & Huber \\
\hline W. & Knogler \\
\hline P. & Husslein \\
\hline P. & Wagenbichler \\
\hline
\end{tabular}

I. Universitäts-Frauenklinik (Vorstand: Prof. E. Gitsch), Wien

Dr. J. C. Huber, I. Universitäts-Frauenklinik Wien, Spitalgasse 23, A-1090 Wien (Österreich)

Zur Pränataldiagnostik von Neuralrohrdysraphien wird seit Jahren das Alphafeto-protein (AFP)

herangezogen. Die Hauptindikation ist dabei das Wiederholungsrisiko, das nach einem

Merkmalsträger bei $5 \%$, nach zwei bei $10 \%$ liegt.

Im Patientengut unserer Zytogenetischen Abteilung befanden sich seit 197645 Frau-en, die

bereits ein Kind mit einem Neuralrohrdefekt geboren hatten - 1 Frau wies ana-mnestisch bereits

zwei Merkmalsträger auf- und bei denen wir aus diesem Grund das AFP aus dem Fruchtwasser

bestimmt haben: bei 4 Patientinnen fand sich abermals eine Dysra-phie, was in unserem kleinen

Kollektiv eine Häufigkeit von über $9 \%$ bedeuten würde.

Die Inzidenz dieser Missbildung ist regional verschieden, in Mitteleuropa liegt sie

durchschnittlich bei 1-2:1000; im Vergleich dazu wird die toxoplasmabedingte Embryopa-thie mit 1:1000, die Phenylketonurie mit 1:10 000 angegeben.

Wegen dieser doch relativ hohen Erkrankungshäufigkeit ging man in verschiedenen Ländern von der Untersuchung im Wiederholungsfall auf ein allgemeines Screening aus

1 Diese Studie wurde durch Unterstützung des Stadtrates für Gesundheit und Sozia-les, Prof. Dr.

Alois Slacker, möglich.

Freie Vorträge

173

dem mütterlichen Serum über; in Osterreich läuft seit März dieses Jahres ein ähnliches

Programm an der I. Universitäts-Frauenklinik: von alien Schwangeren, die an dieser Abteilung

entbinden, wird zwischen der 15. und 20. Schwangerschaftswoche aus dem mütterlichen Serum das AFP bestimmt.

Für die AFP Konzentration im mütterlichen Serum gibt es eine Normalverlaufskurve - die 99.

Perzentile kennzeichnet dabei jene Grenze, ab der mit einer Malformatio gerech-net werden

muss [1].

Neben der praktischen Durchführung des Screenings gingen wir aber auch noch einer

experimentellen Frage nach: wenn man nämlich einen einfachen Übertritt von fetalem AFP in

den mütterlichen Organismus annimmt, müssten in beiden Systemen die AFP-

Konzentrationsmaxima zum gleichen Zeitpunkt auftreten, was jedoch nicht der Fall ist [2]. Die

Erklärung könnte darin liegen, dass es entweder gar nicht zu einem uteroplazentaren Übertritt

kommt und die Mutter selbständig AFP produziert; oder - und das ware die zweite Möglichkeit

- das AFP wird beim Übertritt so verändert, dass aufgrund der unter-schiedlichen Antigenität die

Nachweisgrenzen verschoben sind. 
Zur Beantwortung der ersten Frage versuchten wir zunächst, den Weg des AFP mit-tels indirekter Immunfluoreszenz nachzugehen. Dabei bestätigte sich die fetale Leber als Bildungsort des AFP. Aber auch Plazenta, Amnion und Myometrium wiesen bei gleicher Verdünnung Fluoreszenz und damit in derselben Konzentration AFP auf, was einen direk-ten Übertritt des AFP vom Kind zur Mutter bestätigt.

Um aber die vielleicht unterschiedliche Identität des AFP in beiden Kompartments zu überprüfen, liessen wir AFP-Immunpräzipitate aus dem Fruchtwasser und aus dem mütterlichen Serum auf einem zweidimensionalen Polyamidacrylgel laufen. Obwohl die Präzipitate wegen des fast unter der Nachweisgrenze liegenden AFP sich nur schemenhaft darstellten, konnte man trotzdem sehen, dass der isoelektrische Punkt und damit wahr-scheinlich auch die Molekülstruktur von fetalem und mütterlichem AFP die gleiche ist. Somit konnten wir leider auch auf diese Weise die Frage nach den unterschiedlichen Kon-zentrationsmaxima nicht beantworten. Allerdings kannten wir durch die Immunkomplexe die Position des AFP am Gel: als wir dann fetales, an AFP reichhaltiges Serum auftrennten, fand man an der Position des AFP eine Linie von unterschiedlich isoelektrischer Wertig-keit.

Durch Zufall bekamen wir das Serum eines an Leberkarzinom erkrankten Patienten mit einem ebenfalls hohen neoplastisch bedingten AFP-Gehalt; als wir auch dieses Serum auftrennten, sahen wir, dass nur ein Teil der vorher gezeigten fetalen isoelektrischen Linie exprimiert wurde, allerdings in umso massiverer Weise.

Dies spräche dafür, dass die Expression embryonaler Proteine beim Karzinom modi-fiziert ist, eine Beobachtung, die auch für andere Proteine interessant ware.

Literatur

Gardner, S.; Burton, B.; Johnson, A.: Maternal serum alpha fetoprotein screening: a report of the Forsyth county project. Am. J. Obstet. Gynec. 140: 250-253 (1981). 